\title{
Bariatric Surgery as a Viable Treatment for Idiopathic Intracranial Hypertension: a Case Series and Review of Literature
}

\author{
Vimaladhithan Mahendran ${ }^{1}$ (D) Pol Ricart ${ }^{1} \cdot$ Fridi Levine $^{1} \cdot$ Emma White $^{1} \cdot$ Karen Abolghasemi-Malekabadi $^{1}$. \\ Madeleine Williams ${ }^{1} \cdot$ Martin S Wadley $^{1} \cdot$ Anthony Perry $^{1} \cdot$ Steven John Robinson ${ }^{1}$
}

Received: 2 March 2021 / Revised: 26 June 2021 / Accepted: 9 July 2021 / Published online: 28 July 2021

(C) The Author(s), under exclusive licence to Springer Science+Business Media, LLC, part of Springer Nature 2021

\begin{abstract}
Purpose Idiopathic intracranial hypertension is a significant cause of preventable blindness. Patients suffer from debilitating headaches, pulsatile tinnitus, nausea, vomiting, photophobia and radicular pain. At this rate, treatment cost will increase to 462.7 million pounds sterling annually by 2030 . Weight loss is the only proven disease-modifying therapy for reversal of idiopathic intracranial hypertension. Bariatric surgery leads to superlative weight loss and reversal of related comorbidities. The case series and literature review aim to raise awareness of bariatric surgery as a safe and effective treatment modality for idiopathic intracranial hypertension.

Material and Methods The literature review comprises three systematic analysis and one randomised control trial which were identified after a PubMed search. In the case series, we have included four patients with a preoperative diagnosis of long-standing idiopathic intracranial hypertension. They were referred to our department for bariatric surgery by the neuro-ophthalmologist between January and December 2018. They were followed up for 2 years after bariatric surgery.

Results All four patients were women with a mean age of 34 years. Mean body mass index reduced from $47.3 \mathrm{~kg} / \mathrm{m}^{2}$ before surgery to $30 \mathrm{~kg} / \mathrm{m}^{2}$ at the end of 2 years after surgery. They showed significant improvement or resolution in their symptoms related to idiopathic intracranial hypertension, and none of them required further cerebrospinal fluid pressure reducing procedures.

Conclusion Bariatric surgery is a safe and effective method of treating idiopathic intracranial hypertension. It is superior compared to medical management and cerebrospinal fluid pressure reducing procedures which have high rates of recurrence.
\end{abstract}

Keywords Bariatric surgery $\cdot$ Idiopathic intracranial hypertension $\cdot$ Preventable blindness $\cdot$ Sleeve gastrectomy

\section{Key Points}

1. Idiopathic intracranial hypertension is a significant cause of preventable blindness.

2. Treatment cost is set to increase to 462.7 million pounds sterling annually by 2030 .

3 . Weight loss is the only disease-modifying factor.

4. Bariatric surgery is currently one of the best treatment modalities available to cure this disease.

Vimaladhithan Mahendran

vimaladhithan.m@gmail.com

1 Worcestershire Acute Hospitals NHS Trust, Charles Hastings Way, Worcester, Worcestershire WR5 1DD, UK

\section{Introduction}

Idiopathic intracranial hypertension (IIH) is a debilitating disease that has been increasing steadily over the past few decades and is a significant cause of blindness in the UK [1]. It usually affects young women who suffer from obesity and its related comorbidities. Severe headaches, pulsatile tinnitus, nausea, vomiting, photophobia, radicular pain and progressive loss of vision incapacitate these patients [2,3]. Management is usually medical and surgery reserved for those experiencing visual field defects. Incidence has been estimated at 0.5 to 1 per 100,000 annually, and this is nearly 20 times more common in women with obesity and child-bearing age [1]. Currently, it costs hospitals in England 7016 pounds sterling to care for each one of these patients. If IIH continues to rise as predicted, it will cost 462.7 million pounds sterling for hospitals to treat IIH patients annually by 2031 [1]. 


\section{Material and Methods}

A retrospective analysis of four patients with $\mathrm{IIH}$ referred to the Bariatric Surgery Services at Worcestershire Acute Hospitals NHS Trust between January and October 2018 was performed. All patients had been previously diagnosed with IIH for several years and have been on regular follow-up with the neuro-ophthalmology department at the referring centre. The patients were followed up to 2 years by the bariatric team comprising the bariatric clinical nurse specialist, bariatric dietician, psychologist and surgeon before being discharged to their respective general-practitioner. After being referred by their neuro-ophthalmologist, all patients stay in our Tier 3 weight management service for approximately $6-$ 12 months. During this time, they were screened for sleep apnoea, anxiety, depression, smoking, alcohol intake or abuse, history of neglect or abuse and emotional eating disorder, and referred to psychological or psychiatric services if required. They undergo optimisation of an associated medical condition such as diabetes mellitus. Once patients showed behavioural changes, started losing weight, stopped smoking and controlled their alcohol consumption, they confirmed their interest in bariatric surgery. They will then proceed to our Tier 4 group education sessions about how the surgery works and dietary changes required lifelong.

Finally, they will be discussed at a Bariatric MultiDisciplinary Team (MDT) meeting followed by consultation with the bariatric surgeon. Only patients who underwent laparoscopic sleeve gastrectomy (LSG) or laparoscopic Roux-en-Y gastric bypass (LRYGB) were included for analyses. Any patient who did not proceed to bariatric surgery was excluded from the study. The referral weight, body mass index (BMI), type of surgery (LSG or LRYGB), duration, any immediate or long-term complications, \% total weight loss and total reduction in BMI at 6 months, 12 months and 24 months post-bariatric surgery were recorded. The preoperative and postoperative measurements of CSF opening pressures, visual field defects, visual acuity measures, papilloedema, visual symptoms and headaches, medications and status of other co-morbid conditions were analysed. We also included any previous performed CSF-shunt procedures or optic nerve sheath fenestrations (ONSF) and the need for further such procedures after bariatric surgery.

The literature review was performed by searching for "Bariatric Surgery" and "Idiopathic Intracranial Hypertension" in PubMed on June 2021. The search yielded 77 articles; only systematic reviews and randomised controlled trials were included as they offered the highest level of evidence available. We excluded all other types of studies, including review articles.

\section{Results}

All the four patients with IIH referred to our Tier 3 weight reduction programme during the study period underwent bariatric surgery. All patients were women with a mean age group of 34 years (25-37 years). The mean referral weight was $132.8 \mathrm{~kg}$ (113.4 to $158 \mathrm{~kg}$ ), with a mean preoperative BMI of 47.3 (41.7 to 53.3$) \mathrm{kg} / \mathrm{m}^{2}$.

After 6 months of the surgery, the \% total weight loss was $42 \%$, and BMI was $32 \mathrm{~kg} / \mathrm{m}^{2}$. At 12 months post-surgery, the $\%$ total weight loss was $38 \%$, and BMI reduced to $30 \mathrm{~kg} / \mathrm{m}^{2}$. Finally, two years after the surgery, the $\%$ total weight loss was $39 \%$, and BMI was $30 \mathrm{~kg} / \mathrm{m}^{2}$. Three out of four patients $(75 \%)$ underwent LSG as their primary procedure, whereas one underwent LRYGB. One of the patients (patient 4) who underwent LSG as her initial procedure later had a conversion to LRYGB after 6 months. Except for patient 4, the other three patients did not suffer any immediate or long-term complications due to bariatric surgery (Tables 1,2, and 3).

After her initial LSG, patient 4 developed gastroparesis. She could not tolerate any solid food, so we had to start her on nasojejunal feeds. Four months after her primary operation, she underwent a LRYGB. The length of the biliopancreatic limb was $50 \mathrm{~cm}$, and the alimentary limb measured $100 \mathrm{~cm}$. Unfortunately, on the third postoperative day, she developed a

Table 1 Type of surgery performed

\begin{tabular}{|c|c|c|c|c|c|}
\hline Patient details & Date of birth (dd.mm.yyyy) & Sex & Date of surgery (dd.mm.yyyy) & Type of surgery & Complication \\
\hline Patient 1 & 02.05 .1995 & Female & 22.03 .2018 & LSG & NIL \\
\hline Patient 2 & 11.09.1984 & Female & 20.09 .2018 & LRYGB & NIL \\
\hline Patient 3 & 11.06.1981 & Female & 08.03.2018 & LSG & NIL \\
\hline Patient 4 & 07.01 .1983 & Female & $\begin{array}{l}13.09 .2018 \\
08.02 .2019 \\
11.02 .2019 \\
12.11 .2019\end{array}$ & $\begin{array}{l}\text { LSG } \\
\text { LRYGB } \\
\text { Laparoscopic washout } \\
\text { Redo jejuno-jejunal anastomosis }\end{array}$ & $\begin{array}{l}\text { Gastroparesis } \\
\text { Postoperative leak } \\
\text { Bile acid malabsorption } \\
\text { Bacterial overgrowth }\end{array}$ \\
\hline
\end{tabular}

$L S G$ laparoscopic sleeve gastrectomy; $L R Y G B$ laparoscopic Roux-en-Y gastric bypass 
Table 2 Weight loss

\begin{tabular}{|c|c|c|c|c|c|c|c|c|c|}
\hline $\begin{array}{l}\text { Patient } \\
\text { details }\end{array}$ & $\begin{array}{l}\text { Referral } \\
\text { weight } \\
(\mathrm{kg})\end{array}$ & $\begin{array}{l}\text { Referral } \\
\text { BMI } \\
\left(\mathrm{kgm}^{-2}\right)\end{array}$ & $\begin{array}{l}\text { Preoperative } \\
\text { weight loss } \\
\text { medication }\end{array}$ & $\begin{array}{l}\% \text { total } \\
\text { weight loss } \\
\text { in } 6 \text { months }\end{array}$ & $\begin{array}{l}\% \text { total weight } \\
\text { loss in } 12 \\
\text { months }(\mathrm{kg})\end{array}$ & $\begin{array}{l}\% \text { total weight } \\
\text { loss in } 24 \\
\text { months }(\mathrm{kg})\end{array}$ & $\begin{array}{l}\text { Total BMI loss } \\
\text { in } 6 \text { months } \\
\left(\mathrm{kgm}^{-2}\right)\end{array}$ & $\begin{array}{l}\text { Total BMI loss } \\
\text { in } 12 \text { months } \\
\left(\mathrm{kgm}^{2}\right)\end{array}$ & $\begin{array}{l}\text { Total BMI loss } \\
\text { in } 24 \text { months } \\
\left(\mathrm{kgm}^{-2}\right)\end{array}$ \\
\hline $\begin{array}{c}\text { Patient } \\
1\end{array}$ & 133 & 53 & Nil & $27 \%$ & $30 \%$ & $31 \%$ & 39 & 37 & 36 \\
\hline $\begin{array}{c}\text { Patient } \\
2\end{array}$ & 113 & 42 & Yes, Orlistat & $27 \%$ & $35 \%$ & $35 \%$ & 30 & 27 & 27 \\
\hline $\begin{array}{c}\text { Patient } \\
3\end{array}$ & 159 & 50 & Nil & $69 \%$ & $30 \%$ & $31 \%$ & 36 & 37 & 36 \\
\hline $\begin{array}{c}\text { Patient } \\
4\end{array}$ & 126 & 45 & Yes, Orlistat & $\begin{array}{l}45 \% \\
42\end{array}$ & $\begin{array}{l}56 \% \\
38\end{array}$ & $\begin{array}{l}57 \% \\
39\end{array}$ & 24 & 20 & 21 \\
\hline
\end{tabular}

leak due to disruption of the posterior staple line. She was taken up immediately for a laparoscopic washout.

Following her LRYGB, she developed symptoms of malabsorption and persistent weight loss. The patient was referred to the gastroenterologist, who advised her to undergo a "SeHCAT" (75-selenium homocholic acid taurine) test to rule out bile acid malabsorption and a "hydrogen breath test" to diagnose "small intestinal bacterial overgrowth". Both the SeHCAT test and hydrogen breath test results were positive, confirming that she had developed both bile acid malabsorption and bacterial overgrowth. The gastroenterologist started her on colestipol and rifaximin for 6 months, but this did not significantly improve her symptoms. She continued to suffer from diarrhoea and lose weight. Further, during this period, she also developed intermittent abdominal pain.

Nine months after her LRYGB, she underwent diagnostic laparoscopy. The surgeon found a twist in the Roux-en-Y bypass during the surgery, causing dilatation of the biliopancreatic limb. The surgeon had to convert the surgery into a laparotomy. Next, he had to divide the alimentary limb and anastomose it side to side with the common channel distal to the previous jejuno-jejunostomy. The patient recovered well postoperatively, her symptoms have improved and her weight plateaued.

All four patients were diagnosed as IIH for several years and were under regular follow-up with a neuroophthalmologist and neurologist. They all suffered from severe headache, with one patient having symptoms of blurred vision, progressive visual loss and blackouts. She also suffered from a left superior nasal field defect. The headache and visual symptoms improved in all four patients after their bariatric surgery. The preoperative CSF opening pressures were available for only two patients (30 and $25 \mathrm{~cm}$ of $\mathrm{H} 20$ ); unfortunately, we do not have any records for the other two patients. Postoperative CSF opening pressures were not measured as they were symptomfree. Two patients had papilloedema diagnosed preoperatively on indirect-ophthalmoscopy, both showed resolution postoperatively. None of the patients had previous ONSF procedures before or after bariatric surgery. However, one patient had undergone lumboperitoneal shunt (LP-shunt) in 2011, which had to be revised again in 2013. Finally, the same surgeon performed the primary bariatric procedure in all the patients.

Table 3 Symptoms of idiopathic intracranial hypertension

\begin{tabular}{|c|c|c|c|c|c|c|c|c|}
\hline $\begin{array}{l}\text { Patient } \\
\text { details }\end{array}$ & $\begin{array}{l}\text { CSF opening } \\
\text { pressure } \\
\left(\mathrm{cm} \text { of } \mathrm{H}_{2} \mathrm{O}\right)\end{array}$ & $\begin{array}{l}\text { IIH first } \\
\text { diagnosed }\end{array}$ & $\begin{array}{l}\text { Preoperative } \\
\text { visual field } \\
\text { defect }\end{array}$ & $\begin{array}{l}\text { Preoperative } \\
\text { symptoms }\end{array}$ & $\begin{array}{l}\text { Preoperative } \\
\text { papilloedema }\end{array}$ & $\begin{array}{l}\text { Postoperative } \\
\text { visual field } \\
\text { defect }\end{array}$ & $\begin{array}{l}\text { Postoperative } \\
\text { symptoms }\end{array}$ & $\begin{array}{l}\text { Postoperative } \\
\text { papilloedema }\end{array}$ \\
\hline Patient 1 & 30 & 2017 & $\begin{array}{l}\text { Left superior } \\
\text { nasal } \\
\text { field defect }\end{array}$ & $\begin{array}{l}\text { Severe } \\
\text { headache, } \\
\text { blurred vision }\end{array}$ & Yes & Resolved & $\begin{array}{l}\text { Complete } \\
\text { resolution }\end{array}$ & Resolved \\
\hline Patient 2 & 25 & 2016 & Nil & $\begin{array}{l}\text { Severe } \\
\text { headache, } \\
\text { photophobia }\end{array}$ & Yes & Nil & $\begin{array}{l}\text { Complete } \\
\text { resolution }\end{array}$ & Resolved \\
\hline Patient 3 & N/A & 2011 & Nil & $\begin{array}{l}\text { Severe } \\
\text { headache }\end{array}$ & N/A & Nil & $\begin{array}{l}\text { Complete } \\
\text { resolution }\end{array}$ & N/A \\
\hline Patient 4 & N/A & 2013 & Nil & $\begin{array}{l}\text { Severe } \\
\text { headache }\end{array}$ & Yes & Nil & $\begin{array}{l}\text { Complete } \\
\text { resolution }\end{array}$ & N/A \\
\hline
\end{tabular}

N/A not available; $I I H$ idiopathic intracranial hypertension 


\section{Discussion}

\section{Diagnosis and Management}

In this case series, we have discussed four patients referred to our bariatric services by the neuro-ophthalmologist for refractory IIH. All patients have a long-standing diagnosis and ongoing treatment for IIH. Two patients had been on Orlistat in order to reduce their weight previous to the surgery. All four patients had tried weight loss programmes, slimming clubs and classes to help reduce their weight but failed to sustain their weight loss in the long term.

All patients who underwent bariatric surgery had a followup for a minimum of 2 years postoperatively. In doing so, we aim to raise awareness of bariatric surgery as a safe and effective management option of IIH with long-term remission and improved quality of life.

Patients diagnosed with IIH exhibit the classical signs and symptoms of raised intracranial pressure (ICP); however, diagnosis of IIH is by a lumbar puncture manometry pressure greater than $25 \mathrm{~cm} \mathrm{H} 2 \mathrm{O}$ in the absence of abnormal cerebral anatomy on cross-sectional imaging [4]. The underlying aetiology of IIH is unknown; some theory includes that raised intra-abdominal pressure leads to a cascade of increasing pressures inside the pleura, the atria and the ventricles [5]. Raised central venous pressure reduces the blood flow to the brain and increases intracranial pressure [5]. Most patients can manage with medication alone; the primary therapeutic strategy is to minimise intra-ocular pressure and promote diuresis [6]. This cohort of patients may require a regular spinal tap to give some symptomatic relief [7]. When their vision starts to deteriorate, ONSF and cerebrospinal fluid diversion shunts (ventricle to peritoneal cavity or lumbar spinal canal to peritoneal cavity) are usually recommended $[8,9]$.

The only proven disease-modifying therapy for reversal of IIH is weight loss [10]. In a 10 -year review of 53 patients, Sinclair et al. found that $51 \%$ of patients required shunt revision operations, out of whom, $30 \%$ required multiple revisions [11]. More importantly, the patients continue to gain weight, further exacerbating these symptoms. Although dietary modification and exercise are ideal, most patients with IIH fail to achieve any long-term remission. Bariatric surgery is an attractive treatment option as it leads to superlative weight loss and a reversal in comorbidities such as diabetes, hypertension, obstructive sleep apnoea (OSA), and IIH [12]. Although, as per NICE guidelines, all individuals with a BMI greater than 35 with an associated disease condition (e.g. type II diabetes mellitus) are eligible for bariatric surgery [13], IIH is currently not one of those associated diseases, and most of the patients do not have any other comorbidities. Hence, in the UK, only $0.07 \%$ of patients undergo bariatric surgery for IIH [14].

\section{Review of Literature}

Handley et al. [15] published the first systematic review, which aimed to assess bariatric surgery's efficacy on the treatment of IIH. In total, the authors identified 85 publications after a comprehensive literature review. In the final review, they included 17 papers ( 6 studies and 11 case reports) involving a total of 67 patients. The authors wished to ascertain a range of variables such as age, sex, weight, BMI, symptoms of IIH and most importantly, the difference in lumbar puncture (LP) opening pressure before and after surgery. However, only 12 patients had LP measurements taken preoperatively as well as postoperatively. They showed an average decrease of $18.9 \mathrm{cmH} 2 \mathrm{O}$.

Regarding the rest of the criteria, $92 \%$ of patients showed symptomatic improvement in headache, 93\% had improvement in their visual fields and $88 \%$ reported pulsatile tinnitus resolution. Papilloedema disappeared in $100 \%$ of patients. Of 25 patients who had records of measurements before and after their operation, BMI fell by $17 \mathrm{kgm}^{-2}$.

The author clearly outlines the possible sources of bias that may affect the outcome of the study. Since most of the papers included were case reports, there is a risk of publication bias. The authors were more likely to include those patients who had IIH successfully reversed after bariatric surgery. Patients' self-reporting of resolution of symptoms was then relied upon by many studies, making it difficult to quantify and compare data objectively. It was also important to note that the same author led many of the studies, which formed a series of publications to prove that raised intra-abdominal pressure can cause raised ICP. In summary, the systematic analysis of results confirmed the existence of Level 3 and Level 4 evidence regarding the efficacy of bariatric surgery in the treatment of IIH. This systematic review's main limitation was that most studies included in the analysis were non-randomised, unblinded and had a reasonably small sample size.

Manfield et al. [16] conducted a systematic review of studies that looked at both nonsurgical and surgical interventions for weight loss to treat IIH. They wished to compare the two interventions based on the four broad outcomes. These included visual outcomes, symptoms such as headache, ICP measurement and BMI. After data analysis, they divided the studies into two groups, namely surgical and nonsurgical. The surgical group included seven studies consisting of 65 patients who underwent bariatric surgery for weight loss to treat IIH and a second group composed of 8 studies with 277 patients who underwent nonsurgical interventions to reduce weight to treat IIH. Patients in the surgery group achieved a $100 \%$ resolution of papilloedema and a $90.2 \%$ reduction in headache symptoms. In contrast, nonsurgical methods offered a $66.7 \%$ improvement in papilloedema, $75.4 \%$ in visual field defects and $23.2 \%$ improvement in headache.

The BMI decrease seen in the surgical group was 17.5 vs 4.2 for nonsurgical methods. They also noticed a high 
recurrence rate, $48 \%$ by 36 months, for patients treated with non-bariatric surgical interventions such as CSF shunt procedures used to treat IIH. It is the first study to offer precise data by comparing nonsurgical with surgical methods to reduce BMI and alleviate the symptoms of IIH. This wellconducted systematic analysis with its sizeable patient population convincingly shows the superiority of bariatric surgical interventions over nonsurgical interventions in treating IIH by a marked and sustained reduction in the patient's BMI.

Sun et al. [17] conducted a comprehensive search of existing literature and finally included twelve primary studies $(n=39)$. They aimed to determine the efficacy of bariatric surgery in the treatment of IIH. Out of the 39 participants, 38 were women with an average age of 32.5 years. In this study, the researchers included all types of bariatric surgery. However, most of the patients underwent Roux-en-Y gastric bypass (74\%), followed by adjustable gastric banding (15\%), sleeve gastrectomy $(8 \%)$ and gastric exclusion surgery $(3 \%)$. The average BMI before bariatric surgery was $47.4 \pm 3.6 \mathrm{~kg} / \mathrm{m}^{2}$; this reduced to $33.7 \pm 2.1 \mathrm{~kg} / \mathrm{m}^{2}$ at 6 months and $33.9 \pm 11.6$ $\mathrm{kg} / \mathrm{m}^{2}$ at 12 months after surgery. Concerning the relief in symptoms of IIH, 90\% reported significant improvement in headache, $29 \%$ reported improvement in their visual symptoms and $96 \%$ of patients reported resolution of pulsatile tinnitus. In papilloedema and visual field defects, they were either resolved or stabilised in $88 \%$ and $18 \%$ of patients, respectively. The LP reading after the operation was available in only $4 \%$ of patients; the average opening pressure improved to $14.0 \pm 3.6 \mathrm{cmH} 2 \mathrm{O}$. The authors chose to include all types of bariatric procedures due to the lack of data on bariatric surgery as the treatment mode for IIH. They recommend LRYGB and LSG over gastric banding due to more significant weight loss and low complication rates.

The authors comment that even though there is a strong association between IIH and obesity, IIH is still not widely recognised as an indication for bariatric surgery. As a result, these patients are delayed from getting their bariatric surgery, especially in public health systems where patients are routinely triaged based on their obesity and comorbidity. They conclude by reiterating that the presence of IIH in a patient with obesity must indicate more urgent intervention.

\section{Mollan SP et al. ${ }^{14}$}

Recently Mollan SP et al. published the findings of the first of its kind randomised control trial, which compared bariatric surgery to a community weight management (CWM) intervention. They included 66 women with IIH and a BMI of 35 or higher; they were divided equally into the surgery arm and CWM intervention arm of the study. The mean age was 32 years, $97 \%$ remained in the trial at 12 months, and $81.8 \%$ remained in the trial at the end of 24 months. Most patients in the surgery arm underwent LRYGB (44\%), followed by gastric banding (37\%) and LSG (18.5\%).

The results showed that the ICP was significantly lower in the bariatric surgery arm compared to the CWM arm (adjusted mean [SE] difference, -7.2 [1.8] cm CSF; $95 \% \mathrm{CI},-10.6$ to $-3.7 \mathrm{~cm} \mathrm{CSF} ; P<.001$ ) and at 24 months (adjusted mean [SE] difference, -8.7 [2.0] $\mathrm{cm} \mathrm{CSF} ; 95 \% \mathrm{CI},-12.7$ to $-4.8 \mathrm{~cm}$ $\mathrm{CSF} ; P<.001)$. Weight was significantly lower in the bariatric surgery arm at 12 months (adjusted mean [SE] difference, $-21.4[5.4] \mathrm{kg} ; 95 \% \mathrm{CI},-32.1$ to $-10.7 \mathrm{~kg} ; P<.001)$ and at 24 months (adjusted mean [SE] difference, -26.6 [5.6] kg; $95 \% \mathrm{CI},-37.5$ to $-15.7 \mathrm{~kg} ; P<.001)$. Quality of life was significantly improved at 12 months (adjusted mean [SE] difference, 7.3 [3.6]; 95\% CI, 0.2-14.4; $P=.04$ ) and 24 months (adjusted mean [SE] difference, 10.4 [3.8]; 95\% CI, 3.0-17.9; $P=.006)$ in the bariatric surgery arm.

In the surgery arm, one patient had to return to theatre due to bowel obstruction at the site of mesenteric closure. The patient recovered completely after removing the mesenteric stitch in the CWM arm required CSF diversion procedure for 12 to 24 months. The study's main limitation was the low number of participants in the trial to power the study adequately. As a result, they were unable to recommend one surgical procedure over the other confidently. In this randomised clinical trial, bariatric surgery among patients with active IIH had favourable sustained outcomes concerning reductions in ICP, disease remission and superior quality of life outcomes at 2 years compared with a community weight management intervention [14].

Weight loss is the only disease-modifying factor that is known to cure IIH [10]. Long-term longitudinal studies have demonstrated the efficacy and safety of bariatric surgery in achieving sustained weight loss and resolving other comorbidities such as type 2 diabetes mellitus and sleep apnoea [18].

The data captured in the case series shows four patients who underwent bariatric surgery and demonstrated sustained weight loss over the 2-year postoperative period. Except for one patient, the rest did not experience any immediate or long-term complications secondary to their bariatric surgery. All patients had complete resolution of symptoms secondary to IIH, which resulted in improved quality of life. There was no requirement for shunt surgery or ONSF after the bariatric procedure, nor were they re-admitted with signs and symptoms of raised ICP.

In 2016, the incidence of patients diagnosed with IIH rose from 0.5 previously to 4.69 per 100,000 population. The cost of treating these patients increased from 9.2 million pounds to 49.9 million pounds in 2014 [1]. CSF diversion procedures provide symptomatic relief but do not alter the course of the disease [11]. A 2019 study by J Merola et al. found that bariatric surgery was associated with fifteen times fewer complications than shunt procedures and shorter hospital stay. They also pointed out that the cost of bariatric surgery was recovered within 3 years by 
reduced prescription costs, return to employment and decrease in dependence on disability benefit [19].

Finally, during our time, obesity has reached pandemic proportions. At present bariatric surgery has become mainstream, with more patients wishing to opt for it. However, in countries such as the UK with public healthcare systems, there is a tremendous service strain, often leading to triage patients. Patients suffering from idiopathic intracranial hypertension represent a cohort requiring more urgent intervention. Offering them bariatric surgery earlier could potentially prevent permanent loss of vision. There are considerable benefits in improved quality of life in the long term, reduced hospital admissions and return to work.

\section{Conclusion}

Bariatric surgery is currently one of the best treatment modality for idiopathic intracranial hypertension; the findings of our case series support this important role [17]. Demographic studies suggest that the incidence of idiopathic intracranial hypertension is rising, and therefore, the role of bariatric surgery may become more pivotal in stopping preventable blindness [20].

\section{Declarations}

Ethical Approval This article does not contain any studies with human participants or animals performed by any of the authors. For this type of study formal consent is not required.

Informed Consent Informed consent does not apply.

Conflict of Interest The authors declare no competing interests.

\section{References}

1. Mollan SP, Aguiar M, Evison F, et al. The expanding burden of idiopathic intracranial hypertension. Eye (Lond). 2019;33(3):47885. https://doi.org/10.1038/s41433-018-0238-5. Epub 2018 Oct 24. PMID: 30356129; PMCID: PMC6460708

2. Ko MW. Idiopathic intracranial hypertension. Curr Treat Options Neurol. 2011;13(1):101-8. https://doi.org/10.1007/s11940-0100101-x.

3. Ball $\mathrm{AK}$, Clarke CE. Idiopathic intracranial hypertension. Lancet Neurol. 2006;5(5):433-42. https://doi.org/10.1016/S14744422(06)70442-2.

4. Friedman DI, Jacobson DM. Diagnostic criteria for idiopathic intracranial hypertension. Neurology. 2002;59(10):1492-5. https:// doi.org/10.1212/01.wnl.0000029570.69134.1b.

5. Sugerman HJ, DeMaria EJ, Felton 3rd WL, et al. Increased intraabdominal pressure and cardiac filling pressures in obesityassociated pseudotumor cerebri. Neurology. 1997;49(2):507-11. https://doi.org/10.1212/wnl.49.2.507.
6. Celebisoy N, Gökçay F, Sirin H, et al. Treatment of idiopathic intracranial hypertension: topiramate vs acetazolamide, an openlabel study. Acta Neurol Scand. 2007;116(5):322-7. https://doi. org/10.1111/j.1600-0404.2007.00905.x.

7. Johnston I, Paterson A. Benign intracranial hypertension. II. CSF pressure and circulation. Brain. 1974;97(2):301-12. https://doi.org/ 10.1093/brain/97.1.301.

8. Keltner JL. Optic nerve sheath decompression. How does it work? Has its time come? Arch Ophthalmol. 1988;106(10):1365-9. https://doi.org/10.1001/archopht.1988.01060140529018.

9. Bynke G, Zemack G, Bynke H, et al. Ventriculoperitoneal shunting for idiopathic intracranial hypertension. Neurology. 2004;63(7): 1314-6. https://doi.org/10.1212/01.wnl.0000140699.43019.48.

10. Markey KA, Mollan SP, Jensen RH, et al. Understanding idiopathic intracranial hypertension: mechanisms, management, and future directions. Lancet Neurol. 2016;15(1):78-91. https://doi.org/10. 1016/S1474-4422(15)00298-7. Epub 2015 Dec 8

11. Sinclair AJ, Kuruvath S, Sen D, et al. Is cerebrospinal fluid shunting in idiopathic intracranial hypertension worthwhile? A 10-year review. Cephalalgia. 2011;31(16):1627-33. https://doi.org/10.1177/ 0333102411423305. Epub 2011 Oct 3

12. Gortmaker SL, Swinburn BA, Levy D, et al. Changing the future of obesity: science, policy, and action. Lancet. 2011;378(9793):83847. https://doi.org/10.1016/S0140-6736(11)60815-5. PMID: 21872752; PMCID: PMC3417037

13. Centre for Public Health Excellence at NICE (UK); National Collaborating Centre for Primary Care (UK). Obesity: the prevention, identification, assessment and management of overweight and obesity in adults and children [Internet]. London: National Institute for Health and Clinical Excellence (UK); 2006 Dec.

14. Mollan SP, Mitchell JL, Ottridge RS, et al. Effectiveness of bariatric surgery vs community weight management intervention for the treatment of idiopathic intracranial hypertension: a randomized clinical trial. JAMA Neurol. 2021;26:678-86. https://doi.org/10. 1001/jamaneurol.2021.0659.

15. Handley JD, Baruah BP, Williams DM, et al. Bariatric surgery as a treatment for idiopathic intracranial hypertension: a systematic review. Surg Obes Relat Dis. 2015;11(6):1396-403. https://doi.org/ 10.1016/j.soard.2015.08.497. Epub 2015 Aug 12

16. Manfield JH, Yu KK, Efthimiou E, et al. Bariatric surgery or non-surgical weight loss for idiopathic intracranial hypertension? A systematic review and comparison of meta-analyses. Obes Surg. 2017;27(2):513-21. https://doi.org/10.1007/ s11695-016-2467-7. PMID: 27981458; PMCID: PMC5237659

17. Sun WYL, Switzer NJ, Dang JT, et al. Idiopathic intracranial hypertension and bariatric surgery: a systematic review. Can J Surg. 2020;63(2):E123-8. https://doi.org/10.1503/cjs.016616.

18. Sjöström L, Narbro K, Sjöström CD, et al. Carlsson LM; Swedish Obese Subjects Study. Effects of bariatric surgery on mortality in Swedish obese subjects. N Engl J Med. 2007;357(8):741-52. https://doi.org/10.1056/NEJMoa066254.

19. Merola J, Selezneva L, Perkins R, et al. Cerebrospinal fluid diversion versus bariatric surgery in the management of idiopathic intracranial hypertension. Br J Neurosurg. 2020;34(1): 9-12. https://doi.org/10.1080/02688697.2019.1698012. Epub 2019 Dec 5

20. Kilgore KP, Lee MS, Leavitt JA, et al. Re-evaluating the incidence of idiopathic intracranial hypertension in an era of increasing obesity. Ophthalmology. 2017;124(5):697-700. https://doi.org/10. 1016/j.ophtha.2017.01.006. Epub 2017 Feb 7. PMID: 28187976; PMCID: PMC5637544

Publisher's Note Springer Nature remains neutral with regard to jurisdictional claims in published maps and institutional affiliations. 